\title{
Silences in the LAMs: Digital Surrogacy in the Time of Pandemic, an Introduction
}

In 2018, seven partners within the Philadelphia Area Consortium of Special Collections Libraries (PACSCL) - the College of Physicians of Philadelphia, Thomas Jefferson University, the University of Pennsylvania, Drexel University, Pennsylvania Hospital, The Library Company, and the American Philosophical Society-received funding through the Council on Library and Information Resources (CLIR) Digitizing Hidden Collections program to digitize all extant records documenting early medical education in Philadelphia. This project, For the Health of the New Nation: Philadelphia as the Center of American Medical Education, 1746-1868, will make available through the Internet Archive more than 140,000 images of lecture tickets, course schedules, theses, dissertations, student notes, faculty lecture notes, commencement addresses, opening addresses, and matriculation records that not only document the "greats" in the history of American medicine but also provide access to those silenced voices of people whose medical care provided the basis for medical education.

One planned component of For the Health of the New Nation was a symposium. Rather than invite considered viewpoints in early American medicine, it was decided to broaden the concept, to seek explorations of how the physical/digital duality of primary sources in libraries, archives, and museums - the LAMs - impacts historical research as well as our ability to hear those silenced voices. And so Silences in the LAMs: Digital Surrogacy in the Time of Pandemic was born. Little did we know when planning for the symposium began in earnest in fall 2019 that by spring 2020 we would be living and working within that physical/digital duality. On October 12, 2020, the College of Physicians of Philadelphia, in partnership with the University of Pennsylvania and PACSCL, hosted Silences in the LAMS as a virtual symposium.

PACSCL has a long history of bringing together archivists, librarians, educators, digital humanists, and community activists to create iterations of open-access content digitized from PACSCL partner collections, as well as external collaborators. Founded in 1985 as an informal cooperative group of 16 institutions with a 
shared agenda ranging from access to public programs and development, PACSCL's membership has since more than doubled in size. PACSCL has compiled an impressive track record in developing projects and programs that have greatly benefited member institutions and their diverse constituencies, including the Philadelphia Area Archives Research Portal (http:/ / dla.library.upenn.edu/dla/pacscl/index. html), Bibliotheca Philadelphiensis (http:/ / bibliophilly.pacscl.org/), In Her Own Right: A Century of Women's Activism, 1820-1920 (http:/ / herownright.pacscl.org/), Chronicling Resistance (http: / / resistance.pacscl.org/), and For the Health of the New Nation (http:/ / archive.org/details/fhnn). Participants in the recent symposium focused primarily on access, understandable given the climate in 2020 when special collections were mostly closed and as collections staff were working remotely to meet the needs of their users.

I speak to the choir when I say that books, manuscripts, and photographs are both about something but are also of something. They contain information but, as objects, offer additional data to the savvy researcher. The impact of SARS-CoV-2 has been to severely limit user access to the physical object. Without regard to the increased prevalence of digitized primary sources, the impact of the outbreak begs a question asked by Trevor Owens in 2015: "So, what happens to history when the basis of its sources and evidence becomes increasingly digital? Similarly, what happens to history when its archives become digital?"' I would expand Owens' question and ask, "What happens to history when one cannot access the archives?"

One contributor to this set of articles, Mariam Williams, could not participate in Silences in the LAMS. But Williams' work with Chronicling Resistance, which focuses on the limitations placed on the diverse use of collections by legacy descriptions and institutional barriers, fits seamlessly into the consideration of the physical/digital duality. This pandemic has added yet another layer to the expression of history as a privileged experience.

Melissa Grafe, PhD, John R. Bumstead Librarian for Medical History, Head of the Medical Historical Library at Yale University, opened the symposium with her paper entitled Treating the Disease: The Role of Digital and Physical Primary Sources in Undergraduate Teaching with a look at the duality of physical and digital primary sources, a theme that echoed throughout most of the presentations. Dr. Grafe presents the results of instructor interviews conducted at Yale University in the fall of 2019 as part of a larger Ithaka S+R study. Dr. Grafe notes that, while instructors

1. Trevor Owens, "Digital Sources \& Digital Archives: The Evidentiary Basis of Digital History (Draft)," User Centered Digital Memory (blog), entry posted December 5, 2015, accessed August 13, 2020, www.trevorowens.org/2015/12/ digital-sources-digital-archives-the-evidentiary-basis-of-digitalhistory-draft/. 
and students make heavy use of digital surrogates in their own research, instructors favor use of hard copy sources in their classroom instruction. Physical sources offer students (and researchers) a haptic experience that cannot be replicated in the digital realm. Supplemental skills that accompany use of physical sources, such as learning to discern the information inherent in the physicality of a source, discovering new sources serendipitously, and, in the instructors' minds, removing students from what instructors perceive as a "disembodied" existence, make using physical primary sources a more valuable experience. Dr. Grafe concludes with the idea that, while faculty may prefer that their students engage with physical primary sources, adaptations in teaching to remote audiences may require more reliance on digital surrogates.

In 2006, Dan Cohen and Roy Rosenzweig released the e-book Digital History: A Guide to Gathering, Preserving, and Presenting the Past on the Web. In the introduction, Cohen stated that there are five hazards of negotiating history via the Internet: quality, durability, readability, passivity, and inaccessibility. ${ }^{2}$ The discussions around (in)accessibility centered on the distributive nature of networked information and how that can create new communities of use, as well as the negatives of commercialization, centralization, cost of access, and copyright. In the intervening years we have seen a shift in concerns away from the technical aspects of distributive networks and the cost of accessing stored data and toward issues of how users find and effectively use authentic content. This concern is reflected by Joshua Sternfeld's suggestion that a new field of "digital historiography" be created to reify the interaction of digital technology with historical practice to preserve the "logic of inquiry" that has defined the historical process. ${ }^{3}$ Alexandra Chassanoff, in reviewing the LAIRAH Project (Log Analysis of Internet Resources in the Arts and Humanities), indicated that, in the absence of a physical space (and presumably, physical sources), researchers "require a tremendous amount of information to discern both context and relevance." ${ }^{4}$

Anne Ricculli, PhD, of Drew University, delves into the papers of nineteenthcentury physician Harry Hartshorne to demonstrate to undergraduates how a close reading of one person's papers can teach students how to contextualize other primary sources. Dr. Ricculli's presentation, Curating History in the COVID19 Era: Philadelphia Epidemics and Nineteenth-Century American Women's Medical Education,

2. Daniel J. Cohen and Roy Rosenzweig, "Introduction," Digital History: A Guide to Gathering, Preserving, and Presenting the Past on the Web, accessed September 17, 2020, http:/ / chnm.gmu.edu/digitalhistory/.

3. Joshua Sternfeld, "Archival Theory and Digital Historiography: Selection, Search, and Metadata as Archival Processes for Assessing Historical Contextualization," American Archivist 74, no. 2 (September 2011): 550 .

4. Alexandra Chassanoff, "Historians and the Use of Primary Source Materials in the Digital Age," American Archivist 76, no. 2 (Fall/Winter 2013): 463. 
echoed concerns expressed by Charlotte Lydia Riley that student work in learning systems "erodes" the ability to develop the transferable skills learned through historical research. ${ }^{5}$ Dr. Ricculli worked with undergraduates to develop skills to "anticipate and articulate" challenges faced when they encounter digital surrogates in either learning management systems or elsewhere on the internet. In doing so, Dr. Ricculli posits that students can learn effectively in a digital environment how to assess silences in the historical record as well as within their own research.

One point of access that can frustrate the best of us is working intentionally with student audiences outside the university. Sherman Dorn correctly noted in 2016 that, for most elementary and secondary school teachers, the second-to-last exposure those teachers have to history are the classes taught in high school, followed by one or two survey classes in college depending on their major. ${ }^{6}$ Dorn readily acknowledged that, at times, that education can lack in substance. As Alia Wong noted in an interview with the author of Lies My Teacher Told Me, "By providing students an inadequate history education... America's schools breed adults who tend to conflate empirical fact and opinion, and who lack the media literacy necessary to navigate conflicting information." It is critical, then, to give students access to high-quality primary sources - physical or digital — in an intentional way that facilitates learning. Closures created by the pandemic heightened this need in the spring of 2020 when modifications were made to the Advanced Placement United States History exam, essentially limiting the exam to just document-based questions.

Celia Caust-Ellenbogen, Interim Director, Peace Collections Archives, Friends Historical Library at Swarthmore College, and Jordan Landes, Interim Curator of the Peace Collection and Curator of the Friends Historical Library at Swarthmore College, worked with Robin Landes and Carolyn Fusco, history teachers at Woodbridge Senior High School in Virginia, in addressing the needs created by the abrupt change in the AP exam. Their presentation, DBQ: Document Based Quarantine, outlined how a team of teachers and archivists created slide decks of images from the Swarthmore collections that were paired with Woodbridge's history curriculum. The collection provided content that was shared with students via a "visiting expert" model, embedding collections staff in the classroom. This model, substantiated by student feedback, aided students in social and emotional learning (SEL), providing students with experiences of empathy, relationship-building, and

5. Charlotte Lydia Riley, "Beyond Ctrl-C, Ctrl-V: Teaching and Learning History in the Digital Age," in History in the Digital Age, ed. Toni Weller (London, UK: Routledge, 2013), 159.

6. Sherman Dorn, "Is (Digital) History More Than an Argument about the Past," in Writing History in the Digital Age, eds. Jack Dougherty and Kristen Nawrotzki (Ann Arbor: University of Michigan Press, 2016), 23.

7. Alia Wong, "How History Classes Helped Create a 'Post-Truth' America," The Atlantic, August 2, 2018, accessed September 18, 2020, https:/ / www.theatlantic.com/education/archive/2018/08/historyeducation-post-truth-america/566657/. 
collaboration outside their classrooms. The model points to a direction in which special collections staff can partner with specific schools or school districts to create targeted primary source readers that support both local curricula and student needs. This time-intensive approach may prove an effective model for special collections to embed themselves with intent into local schools, rather than prior models of topically focused content created with little consideration to local needs.

To be literate consumers of historical information, students and other users need to be aware of the subjective, and often limiting, constructs that exist within the archives. Samantha Cutrara critiques the Historical Thinking framework of educating students as being overly laden "within the genealogies of colonialism, imperialism, capitalism, and patriarchy." "Cutrara notes that those of our students and users whose life experiences are outside that imperialist, capitalist world can "articulate two kinds of history: the kind taught in school and the kind taught in their communities." Chronicling Resistance, a PACSCL-sponsored project with funding from the Pew Center for Arts \& Heritage, began in 2018 with a discovery phase to examine many of the issues raised by Cutrara. Mariam Williams, Project Director for Chronicling Resistance, writes in Chronicling Resistance while Cloistered: Overcoming Erasure, Omission \& Alienation in the Archives that the project in its initial iteration had two aims: to amplify stories of past resistance and to help collect and preserve stories of contemporary resistance. In achieving those aims, Williams notes that silences within the archives - those of erasure, omission, and alienation-need to be questioned for that silence to be broached.

In the implementation phase of the project, funded by The Andrew W. Mellon Foundation and the Pew Center for Arts $\&$ Heritage, and in partnership with the Free Library of Philadelphia, Chronicling Resistance will move into an articulation of Cutrara's two kinds of history: an examination of the elements of archival silences that can cause institutional harms, and how that examination can be used to highlight narratives and experiences that expose community-based "lived" history. To achieve this, Williams will work with activist-curators, community-based organizers who will approach archival collections from their areas of experience. The activist-curators will work with collections within the PACSCL membership, exploring not only how legacy descriptions facilitate silences within collections but also how institutional policies of access and use limit community engagement-as well as the documentation of contemporary communities. As noted by one of Williams' community organizers, "The major barrier to connecting communities

\footnotetext{
8. Samantha Cutrara, "The Subjectivity of Archives: Learning from, with and Resisting Archives and Archival Sources in Teaching and Learning History," Historical Encounters: A Journal of Historical Consciousness, Historical Cultures, and History Education 6, no. 1 (2019): 117. For an overview of the Historical Thinking method, see The Historical Thinking Project (https:// historicalthinking.ca/peter-seixas).

9. Cutrara, "The Subjectivity of Archives," 123.
} 
to archives is that a lot of people don't know what materials are available and that they are available to anyone." This point brings my earlier question — that is, "What happens to history when one cannot access the archives?"- to a different level.

The presentations given at Silences in the LAMs focused on the quick responses needed to maintain levels of service to users of special collections and archives during a time of pandemic. The uncertainty we face at the time of this writing - reduced hours, staffing, and, in some instances, funding — suggests that limited access to physical archives may negatively impact how history is examined, written about, and taught. Chronicling Resistance, as well as the other PACSCL-sponsored projects noted here, speak to that different level. The influence of Black Lives Matter since its founding in 2013, made more urgent with the murder of George Floyd, has forced libraries and archives to consider their complicity in how voices are silenced, whether that silencing occurs through proscribed subject headings, intentional ignorance of the contributions made by marginalized groups, or through the fear certain people have of simply visiting a special collection. ${ }^{10}$

PACSCL invites other members of the larger special collections community to reflect on the impact of a pandemic on library and archival services. We invite you to consider the physical/digital duality and the impact of that duality on history and its interpretation. And we ask you to question the issues of context, access, and community that contribute to the silences in the LAMs.

10. For a sampling of recent articles, see Erin Baucom, "An Exploration into Archival Descriptions of LGBTQ Materials," American Archivist 81, no. 1 (March 2018): 65-83; Jarrett M. Drake, "Diversity's Discontents: In Search of an Archive of the Oppressed," Archives and Manuscripts 47, no. 2 (March 28, 2019): 270-79; Anne Ford, "Conscientious Cataloging: Librarians Work to Advance Equity in Subject Headings," American Libraries 51, no. 9/10 (September/October 2020): 16-17; Karin Heffernan, "Loaded Questions: The Framework for Information Literacy through a DEI Lens," College \& Research Libraries News 81, no. 8 (September 2020): 382-86; Alex H. Poole, "Harold T. Pinkett and the Lonely Crusade of African American Archivists in the Twentieth Century," American Archivist 80, no. 2 (September 2017): 296-335. 